MARCIN MAZUR

Polish Academy of Sciences

Institute of Geography and Spatial Organization, Warsaw

m.mazur@twarda.pan.pl

\title{
Method vs. form - an attempt to classify cartographic presentation methods
}

\begin{abstract}
The author of the article discusses the subject of terminology in the field of cartographic methodology. The general purpose is to propose an internally consistent system of concepts which allows classification of cartographic presentation methods based on unambiguous criteria. For this purpose, in the article the concept of presentation method and the concept of presentation form were differentiated, the cartographic presentation method was divided into stages, and possible data transformation and visualization aspects during application of a method were specified. Then, review of the previous classifications of cartographic presentation methods was conducted which allows differentiation of two fundamental approaches to classification and comparison of the applied criteria. On this basis, the author's classification of cartographic presentation methods was suggested in which three qualitative and four quantitative methods were differentiated. It constitutes a compromise between accepting unambiguous criteria and the possibility to differentiate methods fixed in cartographic convention.
\end{abstract}

Keywords: cartographic methodology, presentation method, presentation form, classification of cartographic presentation methods

\section{Introduction}

For many years, attempts to arrange terminology in the field of cartographic methodology have been made. There are two types of results of such attempts. On one hand, differentiation of approaches is beneficial as it allows cartographers certain freedom to adjust the assumed definitions and diverse classifications to particular research objectives. Activities aimed at arranging terminology should not aim to achieve one conceptual system or generally applicable classification. However, on the other hand, ambiguity of concepts and the resulting misunderstandings are related to the diversity of terminology used by cartographers. Therefore, the suggested definitions and classifications should most of all form consistent conceptual systems without internal contradictions. The general purpose of the author of the article is to suggest such an internally consistent system of concepts in the field of cartographic methodology which will allow classification of car- tographic presentation methods based on unambiguous criteria. This general purpose consists of the following detailed purposes:

1) differentiating the concept of presentation method and presentation form,

2) differentiating stages of the cartographic presentation method,

3) systematization of data transformation and visualization manners in the process of cartographic presentation methods,

4) systematization of approaches to classification of cartographic presentation methods,

5) systematization of classification criteria of cartographic presentation methods,

6) suggestion of classification of cartographic presentation methods.

\section{Presentation method vs. presentation form}

"A method is a conscious and repeatable manner of proceedings leading to performance 
of a given task or solution of a problem" (Metoda 1996). From such a definition of a method, dualism of the concept of the cartographic method results which depending on the context is understood by cartographers as a method of research or a method of presentation. The purpose of the cartographic research method is the solution of a certain problem using a map as a source of new information. While the purpose of the cartographic presentation method is to transfer certain information from the author to the map user. However, often the concept of cartographic method is used in a different meaning, not only to define the manner of proceedings, but also to determine the final effect of such proceedings (J. Szaflarski 1965, W. Grygorenko 1970, L. Ratajski 1989). In order to achieve terminological explicitness J. Pasławski (1970) differentiated the two meanings. For the final effect of applying a certain cartographic method, understood as a manner of proceedings, he suggested the term a presentation form. The cartographic presentation form is a graphic expression of application of the method and a link connecting the process of cartographic transfer of information, combining the relation between the editor and the map (cartographic presentation method) with the relation between the map and the user (fig. 1). On one hand, the cartographic presentation form results from the method of proceedings of a map editor, but on the other - it affects the possibility to enrich knowledge as a result of perception of its content. The term perception in this article is understood broadly as a cognitive process involving not only identification and organization of stimuli, but also their interpretation to reflect and understand the environment (D.L. Schacter et al. 2011).

\section{Stages of the cartographic presentation method}

The theory of cartographic communication of information allows to locate cartography in a broader context as science about communication of the sender of information with its recipient using a specific carrier in the form of a map (A. Kolačny 1969). Even though the concept model of the author of a map concerning its subject (step 1), the map function (step 2) and availability and selection of data (step 3)

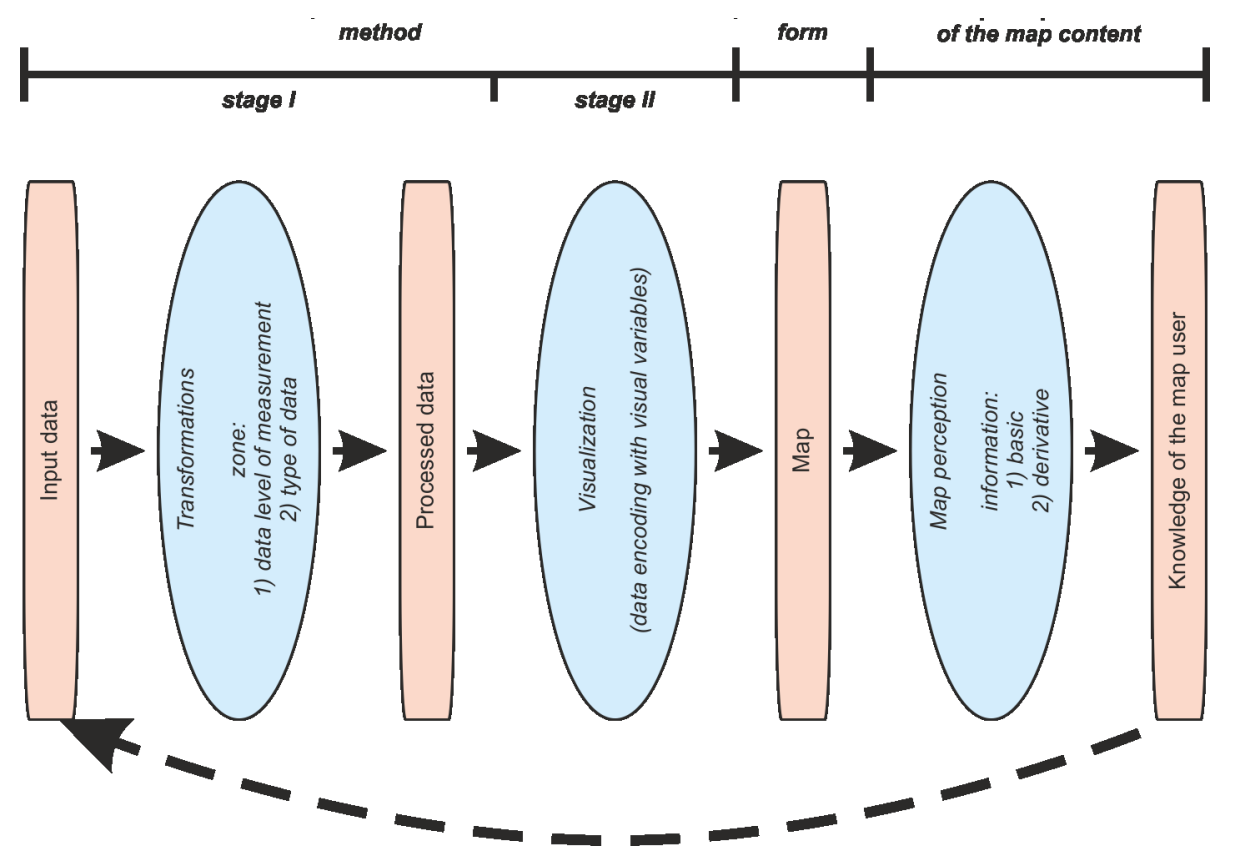

Fig. 1. The scheme of stages of the cartographic presentation method in comparison to the cartographic communication of information (the author's own elaboration based on J. Korycka-Skorupa 2002) 
constitute important factors impacting cartographic communication of information, most of all issues related to development of a map (step 4) and its use (step 5) concern the map itself directly (T.A. Slocum et al. 2005). J. Korycka-Skorupa (2002a, 2002b) calls step 4 being a transition from initial data describing reality to its cartographic presentation form a cartographic method and divides it into two subsequent stages (fig. 1). At the first stage, the author of a map transforms input data which at the second stage is visualized, taking a particular form of a map. Transformation of input data directly affects numerous decisions made at the visualization stage due to the necessity to respect universal principles of graphics (J. Bertin 1967, 1970). Only some combinations of the type of data processed and the manner of its visualization are justified and fixed in the cartographic convention, and some are considered to be unacceptable. However, despite the determined relations between the two stage of the process of the cartographic presentation method, they are formally independent, and the presentation form results directly from the manner of visualization. Therefore, after applying various manners of initial data transformation, the same visualization manner of processed data may occur leading to achievement of the same presentation form. Moreover, some statistical maps developed based on quantitative data can through a defined transformation and visualization manner - have a form typical for qualitative methods. Such a situation occurs among others when various types of typologies of spatial units are presented which leads to assigning spatial units to relevant qualitative categories because of transformation of quantitative data. Examples are classification of spatial units into production and consumption areas, i.e. qualitative categories based on the analysis of quantitative indexes (M. Mazur et al. 2015, J. Bański and M. Mazur 2016).

\section{Systematization of the manners of data transformation and visualization manners in the process of the cartographic presentation method}

Numerous researchers have been involved in the process of transition from data to a map (i.a. A.H. Robinson et al. 1978 and M.-J. Kraak 1998). J. Korycka-Skorupa (2002) differentiates four basic planes of initial data transformation, i.e. transformation of the level of measurement of data, the kinds of manner, the nature and the manner of presenting it as well as four basic aspects differentiating the visualization manner, i.e. determination of cartographic symbols, visual variables, the graphic manner of presentation and the legend of a map. As a result, the combination of choices made within four aspects of input data transformation and four aspects of the processed data visualization manner decide about the presentation method.

The term level of measurement is usually understood in a narrow meaning as a level of measurement of data describing non-spatial attributes of phenomena. In this article, the simplest classification of levels of measurement is used: the qualitative level including the nominal measurement scale and the quantitative level with the following scales: the ordinal, the interval, the ratio and the absolute level (P.H. Lindsay and D.A. Norman 1984). However, the term level of measurement in a broad meaning concerns also two other initial data transformation aspects among the four listed, i.e. the data formulation aspect at the quantitative level - continuous and graduate scales of data as well as the aspects of kinds of data reference are differentiated - there are point references (zero-dimensional), line references (one-dimensional), surface reference (two-dimensional) and volume reference (three-dimensional) (L. Ratajski 1989, W. Ostrowski 2005). In the last aspect, there is also absolute and relative data. Four aspects of input data transformation can be therefore reduced to two spheres:

- level of measurement of data (in a broad sense),

- nature of data at the qualitative level of measurement.

The sphere of the level of measurement of data involves the following transformation planes:

- transformation aspect of the level of measurement of data describing non-spatial attributes,

- generalization ${ }^{1}$ application plane of data at the quantitative level of measurement de-

\footnotetext{
1 Transformation from the continuous to the graduate scale of value must be treated as generalization involving reduction of detail of quantitative information, but within one quantitative level of measurement of data describing non-spatial attributes.
} 
scribing non-spatial attributes by replacing the continuous scale with the graduate scale with a defined frequency distribution (the plane of the data presentation manner),

- possibility to transorm the level of measurement of data (W. Ostrowski 2005) (the plane of the kinds of data reference).

Even though the term visualization is increasingly often used in cartography, it is ambiguous. Usually, it refers to the concept which has been popular since the 90 s of the 20th century (D.R.F. Taylor 1991) and it is identified with the cartographic research method, using modern information and communication technologies. Taking etymology of the word visualization into account, which refers to expressing content in the graphic form allowing visual perception, the meaning of the term visualization in this article was narrowed down to the second stage of the cartographic presentation method, involving information encoding using visual variables differentiating cartographic symbols. The visualization manner of processed data can be described in four aspects:

- cartographic symbols,

- visual variables,

- graphic presentation manner,

- legend of a map.

Cartographic symbols are determined with a number of dimensions. There are point symbols (zero-dimensional), line (one-dimensional), surface (two-dimensional) and volume (three-dimensional) symbols (A.H. Robinson et al. 1995). Due to the two-dimensional nature of maps, volume symbols are the rarest. It is worth noticing that in accordance with the principle of space isomorphism (W. Ostrowski 2008) the visual variable of location is strictly connected to spatial reference of a cartographic symbol, but the number of its dimensions does not have to correspond to the level of measurement of data describing spatial attributes of symbol reference. On statistical maps often a situation occurs where point symbols, e.g. picture symbols or dots, are referred to a statistical space units.

Diversity of the visualization manner results from the selection of visual variables (J. Bertin 1967) and the features of cartographic symbols which do not express information, such as e.g. the size of a dot on a dot map or the shape of diagrams.
The visualization manner also involves the structure of the map legend. Its role is not limited to explanation of particular cartographic symbols; it should also play a role of metadata. Its features determine the manner of using the legend. For instance, after applying a continuous scale of values, using the legend involves estimating values by comparing sizes or the value of symbols on the map with relevant features of standard symbols included in the legend. While, applying a graduate scale, it involves identification of cartographic symbols on the map with standard symbols in the legend. Map users use the legend in various ways due to the manner of data formulation (i.a. I. Frączek 1983, L. Ratajski 1989).

\section{Approaches to the classification of cartographic presentation methods}

The term cartographic method remains a term with numerous meanings even after narrowing its meaning down to the cartographic presentation method, its differentiation from the cartographic presentation form and specifying terminology related to the course of particular method stages. It is confirmed among others by the lack of one commonly used definition of the term cartographic presentation method as well as commonly assumed conditions necessary to acknowledge a given manner of proceedings as a separate method, and not a variant or a specific case of another method.

A consequence of this ambiguity is a variety of approaches to the systematics of cartographic presentation methods. The fundamental tool of these systematics is classification. For the needs of this article, it was assumed that classification consists of a set of classified elements and a classifying function, clearly assigning to each of the classified elements determined conditions differentiating them. In the case of classification of cartographic presentation methods, the set of classified elements is a set of all methods, while the classifying function is clear assignment to a particular method a determined manner of initial data transformation and visualization of such data on a map. Two fundamental elements defining this function are: the field - called a criterion of classification in this case and critical values being limits values within the assumed criterion, separating various methods. 
Depending on the assumed priorities, the overly purpose of classification may be:

1) to determine the set of classified elements or

2) to determine criteria and limits values allowing clear differentiation of such elements.

In the case of the first more frequently used approach to classification of cartographic presentation methods, authors seek to differentiate the most known methods, and then name them. The classification criteria are determined as posteriori and they are used to describe the suggested division of methods and not to create its basis. Therefore, numerous authors of classifications of cartographic presentation methods are content with listing them, while the criteria constituting the basis to differentiate them are nor clearly expressed. Determination of the classification criteria is considered to be a secondary action, therefore limits between different methods can have an unclear nature.

Determination of clear limits between methods is possible, if the assumed criteria are not uniform, i.e. different for different methods. The cause of unclear limits or the necessity to refer to diverse criteria results from the fact that they reflect order fixed in time, when theoretical bases of cartography were only being formed. A characteristic of such an approach to classification is also the fact that it is a two-level approach, as determination of a set of methods is preceded with its division into subsets. For instance, a set of all presentation methods differentiated in a given classification is often divided a priori into a subset of qualitative methods and a subset of quantitative methods. The base of the second level of classification usually includes various criteria often functioning at two different stages of a given method, i.e. one concerning the manner of transformation, and the other concerning the manner of data visualization. After differentiating fundamental methods, authors of classifications sometimes differentiate their subtypes which vary significantly, but according to the assumed criteria and limits values they constitute one method.

Common use of criteria related to data transformation causes that only some classifications of cartographic presentation methods can be simultaneously treated as classifications of cartographic presentation forms. A ne- cessary condition entitling to use the term classification of cartographic presentation forms means use of criteria arising only from the manner of processed data visualization.

\section{Systematization of classification criteria of cartographic presentation methods}

Diversity of classification methods within the first approach listed above is confirmed by the fact that the number of applied classification criteria exceeds the total number of initial data transformation planes and processed data visualization planes. It results from the fact that often the basis of classification of cartographic presentation methods included criteria which were not related to the method itself understood as a process starting from input data to a cartographic presentation form. In literature, the following criteria of classification within the first approach are included:

A) the manner of occurrence of phenomena in geographical space (the method presenting phenomena occurring in geographical space in a continuous or non-continuous manner) a criterion applied at the second level of classification (i.a. U. Freitag 1992);

B) the level of measurement of data describing non-spatial attributes (e.g. qualitative or quantitative method) - a criterion applied at the first level of classification (i.a. A.H. Robinson 1953, L. Ratajski 1973, W. Witt 1973, M.-L. Hsu 1979, D. Unwin 1981, U. Freitag 1992, B.D. Dent 1993, K.C. Clarke 1995) or at the second level of classification (i.a. K. Horn and B.-B. Godesberg 1977);

C) the manner of presenting data at the quantitative level of measurement (the continuous method) or the graduate method - a criterion applied at the second level of classification (i.e. L. Ratajski 1989);

D) the nature of data at the quantitative level of measurement (the absolute or relative data) - a criterion applied at the second level of classification (i.a. W. Witt 1973);

E) the level of measurement of data describing spatial attributes or in other words, a kind of data reference - a criterion applied at the first level of classification (i.a. N.N. Baranskij and A.I. Preobraženskij 1962, K. Horn and B.-B. Godesberg 1977) or at the second level of classifi- 
cation (i.a. N.N. Baranskij and A.I. Preobraženskij 1962, W. Witt 1973);

F) the number of dimensions of a graphic symbol - a criterion applied at the first level of classification (i.a. K. Horn and B.-B. Godesberg 1977) or at the second level of classification (i.a. A.H. Robinson 1953, W. Witt 1973, M.-L. Hsu 1979, D. Unwin 1981, B.D. Dent 1993, K.C. Clarke 1995);

G) informativeness of the presentation form, i.e. the number of information components (e.g. the method with one, two or more components) - a criterion applied at the first level of classification (i.a. J. Bertin 1967 and 1983, U. Freitag 1992);

$\mathrm{H})$ the visual variable encoding the basic information (e.g. the method encoding the basic quantitative information by multiplication identical symbols or by differentiating them according to determined visual variable) - a criterion applied at the second stage of classification (i.a. U. Freitag 1992);

I) the subject of the map - a criterion applied at the first stage of classification (i.a. F.J. Monkhouse and H.R. Wilkinson 1971, K.A. Sališčev 1982);

J) the terminological convention - a criterion applied at the first stage of classification (i.a. K.A. Sališčev 1982) or at the second stage of classification (i.a. W. Witt 1973).

Authors applying the second less frequently represented approach to classify cartographic presentation methods focused on creating a consistent system of criteria and a priori limits values. The effect was a possibility to clearly differentiate methods based on relatively uniform criteria. This approach is useful due to analytical and comparative reasons. However, its fundamental disadvantage is the lack of reference to the cartographic convention concerning classification of presentation methods.

The list of classification criteria of cartographic presentation methods within the second approach is presented in table 1 .

From a review of literature it can be concluded that conventionally differentiated presentation methods cannot be described applying consequently uniform criteria and sharp limits values. Application of such criteria - despite being useful - leads to differentiation of methods which are not fixed in the cartographic conventions, such as e.g. methods differentiated based on the criteria from $D$ to $G$.

\section{Proposal of classification of cartographic presentation methods}

The culmination of considerations within this article is a proposal of classification of cartographic presentation methods based on the possibly small number of such uniform criteria which would ensure its unambiguity, and simultaneously refer to previous classifications and conventional terminology. As a starting point, I assumed the classification suggested by J. Korycka-Skorupa (2002), where criteria $\mathrm{B}, \mathrm{H}$ and $\mathrm{F}$ play the deciding role. An advantage of the classification is the possibility to directly refer the properties of maps developed using cartographic presentation methods to the impact of a determined factor constituting a classification criterion. Among criteria suggested by J. Korycka-Skorupa (2002), only the number of dimensions of a graphic symbol (criterion F) raises doubts. It causes that in some cases methods are differentiated based on a cartographic presentation form, and not the entire proceedings constituting a presentation method. It is likely, the essence of particular presentation methods would be better reflected by the relation manner of processed data (criterion E). It is also one of the reasons why criteria of the classification do not allow to differentiate the isoline method in which a one-dimensional symbol refers to a three-dimensional surface and the basic quantitative information is encoded in it through the location variable and "multiplication of symbols". The classification is also relatively detailed. Therefore, data presentation methods at the ordinal or quantitative level can be treated jointly because as a rule the base to differentiate them is to apply generalization of quantitative information or its lack, and not one of three listed classification criteria.

Qualitative methods initially presented ideas about objects based on their hypothetical appearance. A natural consequence resulting from the need to maintain the isomorphism principles of space seems to be assumption of the criterion of the relation manner of data (criterion E) for the second level of classification of qualitative methods. However, the criterion is sometimes applied inconsistently. Often, the qualitative method involving data refered to both the point and line data is treated as one method - a pictorial method. While data visualization with surface reference is usually divided 
Tab. 1. Selected classification criteria of cartographic symbolization techniques

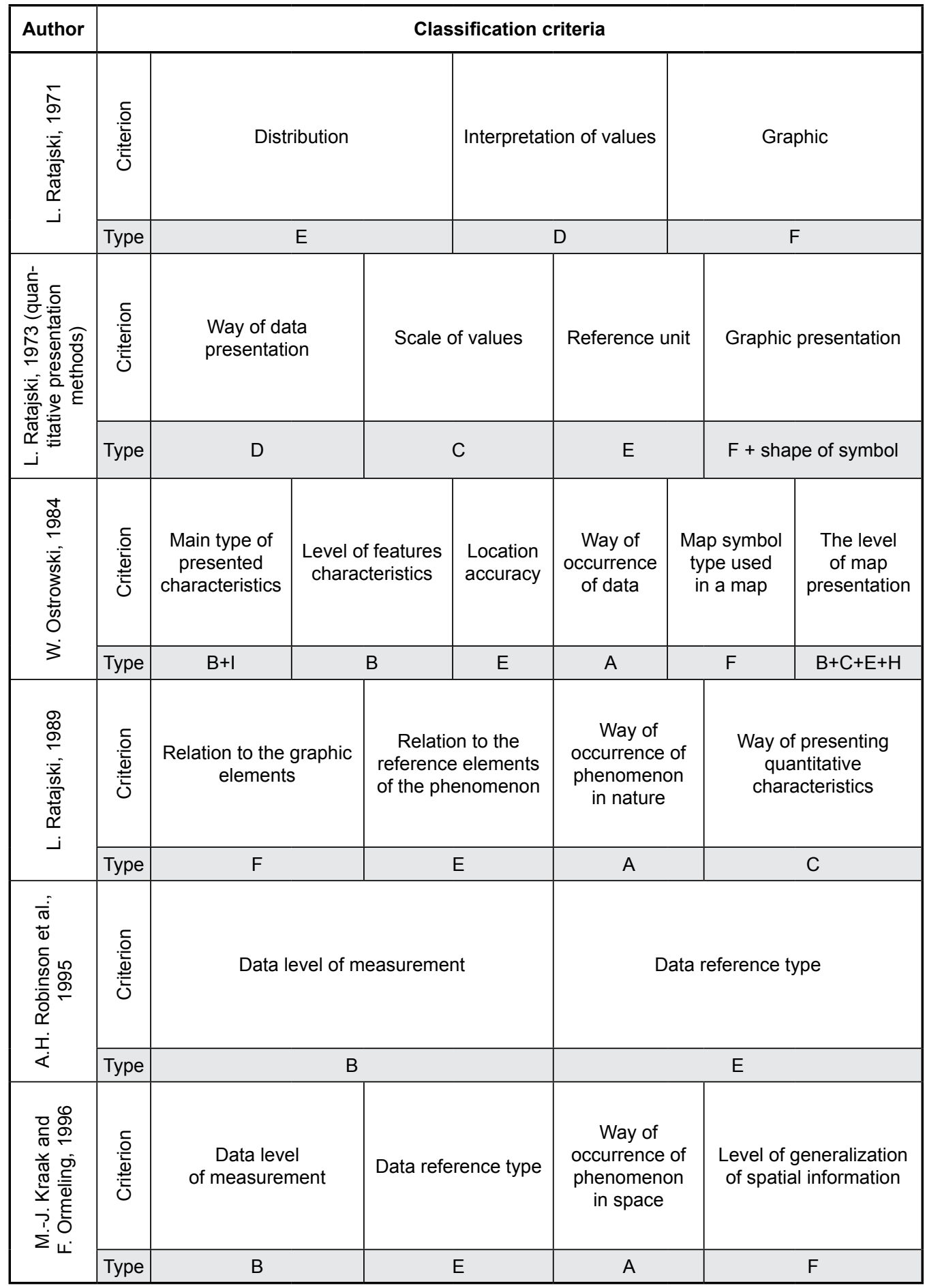


into two separate methods: the range method and the areal quality method (K.A. Sališčev 1982). However, in essence, the last method can be treated as a variant of the range method, or even all qualitative methods as it has a unique feature related to the level of measurement of data. Information on a map presented using other qualitative methods occur at the nominal level of measurement. This means that about a certain point on the map it can be only said whether the presented phenomenon covers it with its range or not. On a map prepared using the areal quality method, all points of the presented area are also classified at the nominal level, but it is also possible to assign one of numerous possible qualitative categories to each point on the map, e.g. one of 50 states in the USA. Therefore, the level of measurement of data constitutes a criterion not only at the first, but also at the second level of classification in the case of qualitative methods. At the second level of classification, the criterion of the level of measurement has two different aspects functioning simultaneously. The method of the areal quality is differentiated based on a detailed level of measurement of data describing non-spatial attributes (criterion B), while the pictorial method is differentiated based on the level of measurement of data describing spatial attributes (criterion E). In the case of the pictorial method, further division into point symbols and line symbols seems logical, and therefore due to the number of dimensions of a symbol (criterion $\mathrm{F}$ ).

Criteria applied at the second level of classification of qualitative presentation methods are not sufficient for clear differentiation of quantitative methods. Each of four most frequently differentiated quantitative methods: the dot method, the choropleth method, the diagram method and the isoline method, can occur with any manner of data reference (criterion $\mathrm{E}$ ). Dots on dot maps can be topographically or uniformly distributed. A diagram may present data referred to a point, a line or a surface. A reference field of a choropleth map is most frequently a determined spatial unit, while the isoline method is used to present processed data in the form of a three-dimensions statistical surface which determined the level of measurement of data describing spatial reference attributes of cartographic symbols. Initial data until the moment of commencing transformation (interpolation) can describe spatial attributes at various levels of measurement. The shape of a surface obtained as a result of applying the isoline method can result from mapping of the actual three-dimensional surface, e.g. surface area or from an abstract statistical surface based on data related to point, line or a surface.

Detailed criterion B cannot be assumed as the basis for classification of quantitative methods. Quantitative methods can present quantitative data at the ordinal, interval, ratio or absolute level of measurement as well as quantitative data generalized applying frequency distribution.

As opposed to qualitative methods, the basis of the second level of classification of qualitative presentation methods can be a criterion related not only to one stage, but also to one aspect. While, at the second level of the classification of qualitative methods applied in the article, the level of measurement of data describing attributes of phenomena plays a deciding role, the quantitative methods at the second level are classified according to the criterion of visual variable (criterion $\mathrm{H}$ ). The criterion does not concern data describing attributes of phenomena or their transformation manner, but it results directly from the second stage of cartographic presentation method - the manner of visualization of processed data.

The list of criteria of classification of cartographic presentation methods assumed in this article is presented in fig. 2 . In the case of each of four quantitative methods, the isomorphism principle is kept because of encoding of spatial information using the location visual variable of a symbol (spatial isomorphism). To encode quantitative information, various visual variables were used (isomorphism of content). However, attention must be paid to the case of two methods which concerning the manner of encoding quantitative information are specific. Specificity of the dot method involves expressing quantitative information not by differentiation of symbols using a separate visual variable, but using an appropriate number of identical symbols. Only their total size is proportional to data and it can be treated as a visual variable of size or value. Specificity of the isoline method involves an unusual manner of encoding the basic quantitative information. Particular isolines differ from one another with their location and orientation. Orientation of a line symbol represents the direction of constant data values, i.e. simul- 


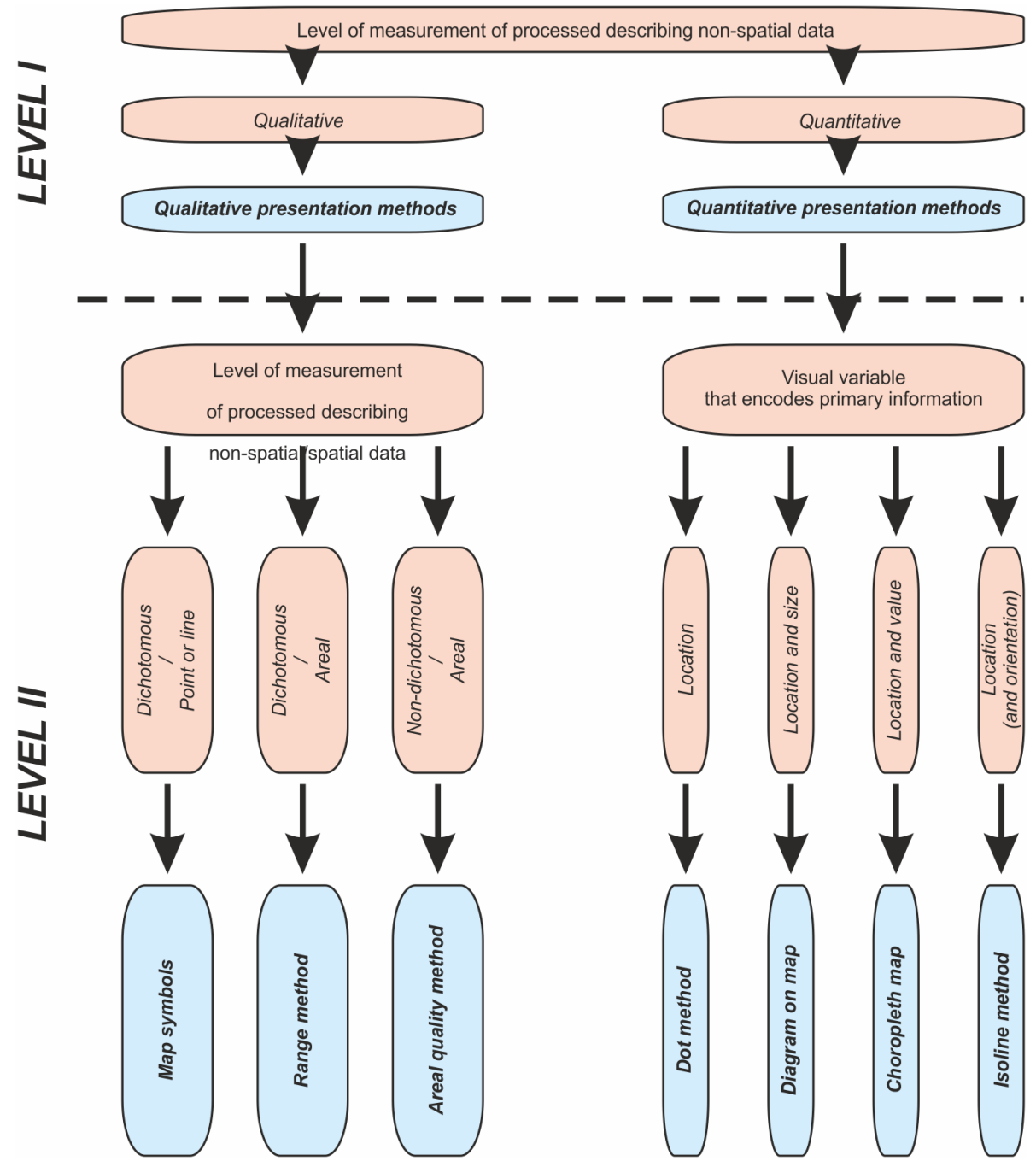

Fig. 2. The scheme of classification criteria and cartographic presentation methods differentiated using them (the author's own elaboration)

taneously non-spatial information (determined data value) and spatial information (mutual location of points with this value). In this regard, application of the variable of orientation in the isoline method is not similar to the use of visual variables used to encode the basic quantitative information in the case of other quantitative methods which are independent of the location variable.

In the context of relations occurring between data transformation in the cartographic presen- tation method and classification of methods, it can be stated that it does not determine the possibilities of using a particular quantitative presentation method ${ }^{2}$. The diagram method or the isoline method can present data with an absolute nature (e.g. annual precipitation total)

\footnotetext{
${ }^{2}$ Quantitative methods are definitely more often used to visualize processed data occurring in the graduate or continuous frame and with the point, surface or volume manner of its reference. However, such a general regularity does not constitute a strict rule.
} 
or a relative nature (e.g. gross domestic product per resident); while it is assumed that the dot method is used to present data with an absolute nature, and the choropleth method to present data only with a relative nature.

\section{Conclusions}

Application of an internally consistent terminological system in scientific research, including cartographic research, is essential. The example of such a system presented in the article shows the benefits of the effort made.

First of all, specification of the meaning of commonly used cartographic terms allow in a logical way to explain numerous phenomena observed by cartographers as well as editing principles which - despite being known, accepted and applied in cartographic practice for many years - can be only justified by the intuition and experience of the editor or fixed convention.

\section{Literature}

Bański J., Mazur M., 2016, Classification of rural areas in Poland as an instrument of territorial policy. "Land Use Policy" No. 54, pp. 1-17.

Baranskij N.N., Preobraženskij A.I., 1962, Ekonomičeskaja kartografija. Moskva: Gosudarstvennoe Izdatelstwo Geografičeskoj Literatury.

Bertin J., 1967, Semiologie graphique. Les diagrammes, les reseaux, les cartes. 2nd ed. 1973, La Haye-Paris: Mouton et Gouthier-Villars.

Bertin J., 1970, La graphique. „Communications” Vol. 15, pp. 169-185. Polish transl.: Grafika. „Przegląd Zagranicznej Literatury Geograficznej” 1971, nr 1/2, pp. 9-31.

Bertin J., 1983, Semiology of graphics: Diagrams, networks, maps. Madison: The University of Wisconsin Press.

Clarke K.C., 1995, Analytical and computer cartography. 2nd ed., Englewood Cliffs: Prentice Hall.

Dent B.D., 1993, Cartography: Thematic map design. 4th ed., Dubuque: W.C. Brown Publishers.

Frączek I., 1983, Konstrukcja legendy kartodiagramów (na przykładzie polskich atlasów regionalnych). „Polski Przegląd Kartograficzny” T. 15, nr 3, pp. 113-126.

Freitag U., 1992, Cartographic conceptions: contributions to theoretical and practical cartography 1961-1991. „Berliner geovissenschaftliche Abhandlungen" Ser. C, Bd. 13.

Grygorenko W., 1970, Redakcja i opracowanie map ogólnogeograficznych. Warszawa: PPWK.
Second of all, application of uniform criteria of classification of cartographic methods allows explanation of properties of maps made using particular methods. Therefore, such classification is extremely useful due to analytical and comparative reasons. However, in the case of cartographic presentation methods, development of such classification is extremely difficult as fixed classifications function in cartography the basis of which are not uniform criteria. The classification suggested in this article constitutes an example of a certain compromise. On one hand, a set of methods compliant with cartographic conventions was obtained, on the other - uniform criteria constituting the basis to classify quantitative methods were obtained which allows their properties to be referred to the impact of a determined factor, and in this case to the visual variable used to encode information.

Horn K., Godesberg B.-B., 1977, Integriertes System zur kartographischen Darstellung von Planungsinformationen. In: Thematische Kartographie und elektronische Dateverarbeitung. Hannover: Hermann Schroeder Verlag KG, „Forschungs- und Sitzungsberichte" Bd. 115, pp. 173-180.

Hsu M.-L., 1979, The cartographer's conceptual process and thematic symbolization. „The American Cartographer" Vol. 6, no. 2, pp. 117-127.

Kolačny A., 1969, Cartographic information - a fundamental concept and term in modern cartography. "The Cartographic Journal" Vol. 6, no. 1, pp. 47-49.

Korycka-Skorupa J., 2002, Od danych do mapy. „Polski Przegląd Kartograficzny” T. 34, no. 2, pp. 91-102; no.3, pp. 175-188.

Kraak M.-J., 1998, The cartographic visualization process: from presentation to exploration. "The Cartographic Journal” Vol. 35, no. 1, pp. 11-15.

Kraak M.-J., Ormeling F., 1996, Cartography: Visualization of spatial data. London: Addison Wesley Longman Limited. Polish transl.: Kartografia, wizualizacja danych przestrzennych. Warszawa: Wydawnictwo Naukowe PWN, 1998.

Lindsay P.H., Norman D.A., 1984, Procesy przetwarzania informacji u człowieka. Wprowadzenie do psychologii. Warszawa, PWN.

Mazur M., Bański J., Czapiewski K., Śleszyński P., 2015, Wiejskie Obszary Funkcjonalne - próba metodyczna wyznaczenia ich obszarów i granic. In: M. Biczkowski, L. Kozłowski (eds.), Wiejskie 
obszary funkcjonalne. „Studia Obszarów Wiejskich" T. 37, pp. 7-37.

Monkhouse F.J., Wilkinson H.R., 1971, Maps and diagrams. Their compilation and construction. London: Methuen and Corporation Limited.

Metoda, 1996. In: „Nowa encyklopedia powszechna PWN" T. 4, p. 178, Warszawa: Wydawnictwo Naukowe PWN.

Ostrowski W., 1984, Próba klasyfikacji metod kartograficznych. In: Teoretyczne i metodyczne problemy współczesnej kartografii. „Materiały Ogólnopolskich Konferencji Kartograficznych" T. 10, Lublin, pp. 95-111.

Ostrowski W., 2005, Transformacja teorii w praktycznym redagowaniu mapy. In: Projektowanie i redakcja map. „Główne problemy współczesnej kartografii", Wrocław, pp. 38-47.

Ostrowski W., 2008, Semiotyczne podstawy projektowania map topograficznych. Warszawa: Uniwersytet Warszawski.

Pasławski J., 1970, O kartograficznej metodzie badań. „Przegląd Geograficzny” T. 42, nr 4, pp. 713-719.

Pasławski J., 1993, O kartogramie diagramicznym. „Polski Przegląd Kartograficzny” T. 25, nr 2, pp. 57-65.

Ratajski L., 1971, Podstawy definicji i terminologii metod kartograficznych. In: Problemy kartografii tematycznej. „Materiały Ogólnopolskich Konferencji Kartograficznych" T. 1, Lublin - Warszawa, pp. 249-264.

Ratajski L., 1973, Metodyka kartografii społeczno-gospodarczej. 1st ed., Warszawa: PPWK.

Ratajski L., 1989, Metodyka kartografii społeczno-gospodarczej. 2nd ed., Warszawa: PPWK.
Robinson A.H., 1953, Elements of cartography. 1st ed., New York - London: John Wiley and Sons, Chapman and Hall Limited.

Robinson A.H., Morrison J.L., Muehrcke Ph.C., Kimereling A.J., Guptill S.C., 1995, Elements of cartography. 6th ed., New York: John Wiley and Sons.

Robinson A.H., Sale R.D., Morrison J.L., 1978, Elements of Cartography. 4th ed., New York: John Wiley and Sons. Polish transl.: Podstawy kartografii. Warszawa: Wydawnictwo Naukowe PWN, 1988.

Sališčev K.A., 1982, Kartovedenie. Moskva: Izdatelstvo Moskovskogo Universiteta. Polish transl.: Kartografia ogólna. Warszawa: Wydawnictwo Naukowe PWN, 1998.

Schacter D.L., Gilbert D.T., Wegner D.M., 2011, Psychology. 2nd ed., New York: Worth Publishers.

Slocum T.A., MacMaster R.B., Kessler F.C., Howard H.H., 2005, Thematic cartography and geographic visualization. 2nd ed., "Prentice Hall Series in Geographic Information Science", Pearson Prentice Hall, Upper Saddle River.

Szaflarski J., 1965, Zarys kartografii. 2nd ed., Warszawa: PPWK.

Taylor D.R.F. (ed.), 1991, Geographic information systems: The microcomputer and modern cartography. Oxford: Pergamon.

Unwin D., 1981, Introductory spatial analysis. London: Methuen and Corporation Limited.

Witt W., 1973, Thematische Kartographie. Methoden und Probleme. Tendenzen und Aufgaben. 2nd ed., Hannover: Gebruder Janecke Verlag. 